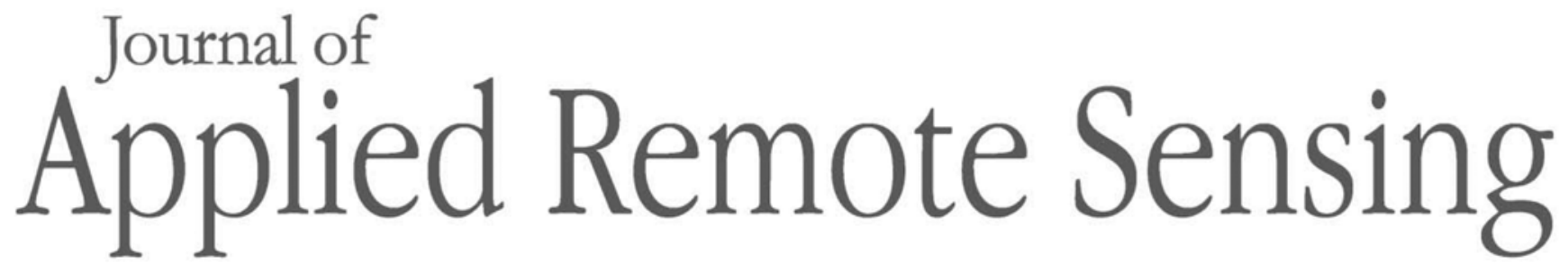

RemoteSensing.SPIEDigitalLibrary.org

\title{
Crop classification from Sentinel-2- derived vegetation indices using ensemble learning
}

Rei Sonobe

Yuki Yamaya

Hiroshi Tani

Xiufeng Wang

Nobuyuki Kobayashi

Kan-ichiro Mochizuki 


\title{
Crop classification from Sentinel-2-derived vegetation indices using ensemble learning
}

\author{
Rei Sonobe, ${ }^{\mathrm{a}, *}$ Yuki Yamaya, ${ }^{\mathrm{b}}$ Hiroshi Tani, ${ }^{\mathrm{c}}$ Xiufeng Wang, \\ Nobuyuki Kobayashi, ${ }^{d}$ and Kan-ichiro Mochizuki ${ }^{\mathrm{e}}$ \\ ${ }^{a}$ Shizuoka University, Faculty of Agriculture, Shizuoka, Japan \\ ${ }^{b}$ Hokkaido University, Graduate School of Agriculture, Sapporo, Japan

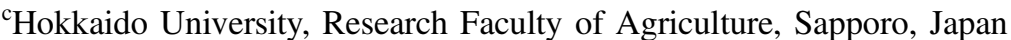 \\ ${ }^{\mathrm{d}}$ Smart Link Hokkaido, Iwamizawa, Japan \\ ${ }^{\mathrm{e}} \mathrm{PASCO}$ Corporation, Tokyo, Japan
}

\begin{abstract}
The identification and mapping of crops are important for estimating potential harvest as well as for agricultural field management. Optical remote sensing is one of the most attractive options because it offers vegetation indices and some data have been distributed free of charge. Especially, Sentinel-2A, which is equipped with a multispectral sensor (MSI) with blue, green, red, and near-infrared-1 bands at $10 \mathrm{~m}$; red edge 1 to 3, near-infrared-2, and shortwave infrared 1 and 2 at $20 \mathrm{~m}$; and 3 atmospheric bands (band 1, band 9, and band 10) at $60 \mathrm{~m}$, offer some vegetation indices calculated to assess vegetation status. However, sufficient consideration has not been given to the potential of vegetation indices calculated from MSI data. Thus, 82 published indices were calculated and their importance were evaluated for classifying crop types. The two most common classification algorithms, random forests (RF) and support vector machine (SVM), were applied to conduct cropland classification from MSI data. Additionally, super learning was applied for more improvement, achieving overall accuracies of $90.2 \%$ to 92.2\%. Of the two algorithms applied (RF and SVM), the accuracy of SVM was superior and $89.3 \%$ to $92.0 \%$ of overall accuracies were confirmed. Furthermore, stacking contributed to higher overall accuracies $(90.2 \%$ to $92.2 \%)$, and significant differences were confirmed with the results of SVM and RF. Our results showed that vegetation indices had the greatest contributions in identifying specific crop types. (c) 2018 Society of Photo-Optical Instrumentation Engineers (SPIE) [DOI: 10.1117/1.JRS.12.026019]
\end{abstract}

Keywords: crop; random forests; Sentinel-2; stacking; support vector machine; vegetation index.

Paper 180133 received Feb. 12, 2018; accepted for publication May 7, 2018; published online May 18, 2018.

\section{Introduction}

From a land-planning perspective, cropland diversity is vital and crop cover maps provide information for estimating potential harvest and agricultural field management. To document field properties, such as cultivated crops and locations, some local governments in Japan have been using manual methods. ${ }^{1}$ However, more efficient techniques are required to reduce the high expense of these methods. Thus, satellite data-based cropland mapping has gained attention. Some spectral indices, which are combinations of spectral measurements at different wavelengths, have been used to evaluate phenology or quantify biophysical parameters. ${ }^{2-5}$ As a result, they have also made crop maps more accurate in previous studies, ${ }^{6}$ and the abilities of optical remote sensing data have been improved for monitoring agricultural fields. The opportunities to obtain optical remote sensing data have improved due to the Sentinel-2A satellite launch on June 23, 2015. Now, it is collecting multispectral data including 13 bands covering the visible, shortwave infrared bands (SWIR) wavelength regions. Sentinel-2B, which possesses the same

*Address all correspondence to: Rei Sonobe, E-mail: reysnb@gmail.com

$1931-3195 / 2018 / \$ 25.00$ (C) 2018 SPIE 
specifications, was launched on March 7, 2017, and creates greater opportunities for monitoring agricultural fields. Furthermore, various spectral indices can be extracted including indices based on SWIR, which are influenced by plant constituents, such as pigments, leaf water contents, and biochemicals. ${ }^{7,8}$ Furthermore, vegetation indices derived from reflectance data acquired from optical sensors have been widely used to assess variations in the physiological states and biophysical properties of vegetation. ${ }^{9-11}$ Specifically, the normalized difference vegetation index (NDVI), ${ }^{12}$ soil-adjusted vegetation index (SAVI), ${ }^{13}$ and enhanced vegetation index $(\mathrm{EVI})^{14}$ have been used for monitoring vegetation systems or ecological responses to environmental change. ${ }^{15}$ Multispectral sensor (MSI) data have been used for identifying crop types,${ }^{16-18}$ plastic-covered greenhouses, ${ }^{19}$ water bodies,${ }^{20}$ and some previous studies showed the potential of VIs calculated from MSI data. However, it is possible to calculate a vast number of VIs from MSI data and most of them have been ignored in the previous studies. In this study, 82 published indices and original reflectance data sources were evaluated to classify six crop types including beans, beetroot, grass, maize, potato, and winter wheat, which are dominant crops on the western Tokachi plain, Hokkaido, Japan.

In addition to qualities of remote sensing data, classification algorithms are important to improve classification accuracies of crop maps. Recently, random forests (RF) is a widely used machine learning algorithm consisting of an ensemble of decision trees, and it has been an extremely successful machine learning algorithm for classification and regression method. ${ }^{21}$ It has been applied for generating land cover maps ${ }^{22,23}$ and reached around 65\% (tree species identification), ${ }^{17} 76 \%$ (crop types identification), ${ }^{17}$ and $90 \%$ (greenhouse detection) ${ }^{19}$ using MSI data in the previous studies.

Some studies showed that support vector machine (SVM) performed better than RF for this purpose, and it has been widely applied for crop-for-crop classification. ${ }^{22,24-26}$ Its robustness to outliers has been demonstrated and SVM is an excellent classifier when the number of input features is large. ${ }^{27}$

The superlearner (SL) methodology, ${ }^{25}$ also called stacking, is an ensemble learning method in which the user-supplied library of algorithms is combined through a convex weighted combination, with the optimal weights to make the cross-validated empirical risk smaller. Therefore, SL could be expected to classify crop types more accurately than the single use of RF or SVM, both considered in this study. Next, an ensemble approach based on SL was applied for improving classification accuracies.

Within this framework, the main objectives of the present study were to evaluate the potential of Sentinel-2 data for crop-type classification and the potential of ensemble learning based on RF and SVM.

\section{Materials and Methods}

\subsection{Study Area}

The study area was located in the western part of Tokachi plain, Hokkaido, Japan (Fig. 1, 142 $42^{\prime}$ $51^{\prime \prime}$ to $143^{\circ} 08^{\prime} 47^{\prime \prime} \mathrm{E}, 42^{\circ} 43^{\prime} 20^{\prime \prime}$ to $43^{\circ} 07^{\prime} 24^{\prime \prime} \mathrm{N}$ ). Main cultivated crop types are beans, beetroots, grasses, maize, potatoes, and winter wheat. The average monthly temperatures were $8.3^{\circ} \mathrm{C}$ to $21.8^{\circ} \mathrm{C}$ and monthly precipitation was 12.0 to $94.5 \mathrm{~mm}$ from May to October.

Field location and attribute data, such as crop types, were based on manual surveys and provided by Tokachi Nosai (Obihiro, Hokkaido) as a polygon-shaped file. A total of 12,639 fields [2265 beans fields, 1548 beetroot fields, 2110 grasslands (timothy and orchard grass), 1000 maize fields, 2452 potato fields, and 3264 winter wheat fields] were observed. The fields ranged from 0.05 to 18.21 ha with an averaged value of 2.54 ha. Grasslands were located on the outskirts of the built-up area.

\subsection{Remote Sensing Data}

The data acquired from Sentinel-2 MSI contained blue, green, red, and near-infrared-1 bands at $10 \mathrm{~m}$; red edge 1 to 3, near-infrared-2, and SWIR 1 and 2 at $20 \mathrm{~m}$; and three atmospheric bands 


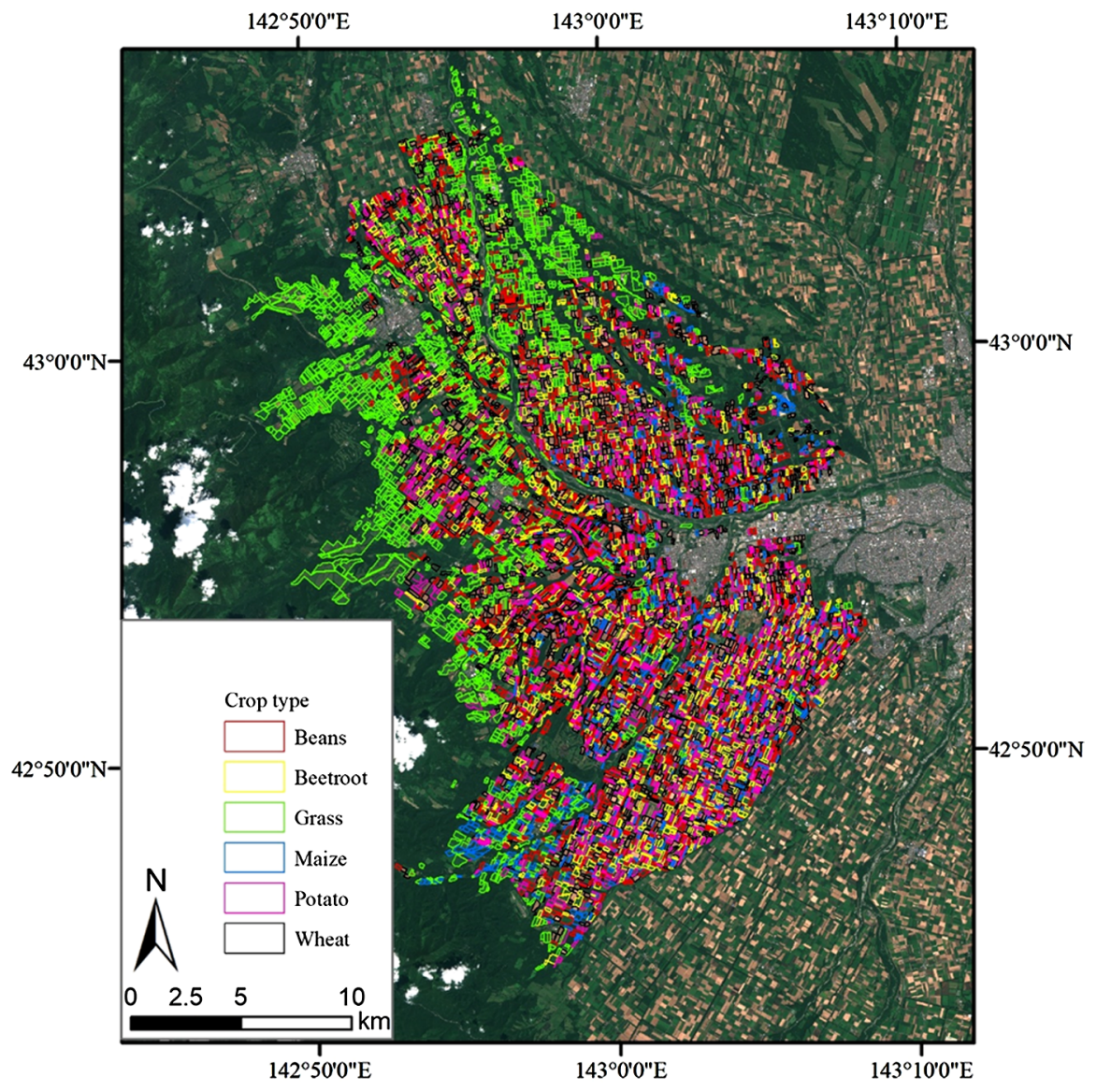

Fig. 1 Study area and the distribution of croplands (background map shows Sentinel-2A data obtained on August 11, 2016, R: band 4, G: band 3, and B: band 2).

(band 1, band 9, and band 10) at $60 \mathrm{~m}$. In this study, the three atmospheric bands were removed, because they were dedicated to atmospheric corrections and cloud screening. ${ }^{28}$

Although Sentinel-2A imagery was gathered seven times from May to September 2016, for the whole site, all images were covered with clouds except for one acquired on 11 August. The level 1C data acquired on August 11, 2016, were downloaded from EarthExplorer. ${ }^{29}$ All bands were converted to $10-\mathrm{m}$ resolution with a cubic convolution resampling method and average reflectance values of each band were calculated for each field using the field polygons to compensate for spatial variability and to avoid problems related to uncertainty in georeferencing.

Some vegetation indices, such as NDVI, have been used for improving classification accuracies in previous studies. ${ }^{16,22,30,31}$ About 82 published vegetation indices for evaluating various vegetation properties were calculated in this study (Table 1).

\subsection{Classification Algorithm}

All samples were divided into the following three groups using a stratified random sampling approach: training data (50\%) for developing classification models, validation data (25\%) for hyperparameter tuning, and test data $(25 \%)$ for evaluation of classification accuracies ${ }^{86}$ and Table 2 shows the numbers of fields of each crop type.

SVM partitions data using maximum separation margins ${ }^{87}$ and the "kernel trick" has frequently been applied instead of attempting to fit a nonlinear model in previous studies. ${ }^{30}$ In this study, the Gaussian radial basis function kernel, which has mostly been used for classification purposes ${ }^{30}$ was used as a kernel and two parameters were tuned to control the flexibility of the classifier, the regularization parameter $C$, and the kernel bandwidth $\gamma$. If the $C$ value is too large, there is a high penalty for no separable points, and we may store many support vectors and 
Sonobe et al.: Crop classification from Sentinel-2-derived vegetation indices...

Table 1 Vegetation indices calculated from Sentinel-2 MSI data.

\begin{tabular}{|c|c|c|}
\hline Abbreviation & Index & Formula \\
\hline AFRI1. $6^{32}$ & Aerosol free vegetation index 1.6 & $\frac{\text { Band } 8 a-0.66 * \text { Band } 11}{\text { Band } 8 a+0.66 * \text { Band } 11}$ \\
\hline AFRI2.132 & Aerosol free vegetation index 2.1 & $\frac{\text { Band } 8 a-0.5 * \text { Band } 12}{\text { Band } 8 a+0.5 * \text { Band12 }}$ \\
\hline $\mathrm{ARI}^{33}$ & Anthocyanin reflectance index & $\frac{1}{\text { Band3 }}-\frac{1}{\text { Band5 }}$ \\
\hline \multirow[t]{2}{*}{$A R V I^{34}$} & Atmospherically resistant vegetation index & $\left.\frac{\{\text { Band8- }}{\{\text { Band }} \frac{\text { Band }-\gamma(\text { Band2-Band4 })]\}}{\text { Band4 }-\gamma(\text { Band2-Band4 })\}}\right\}$ \\
\hline & & $\begin{array}{l}\text { The } \gamma \text { is a weighting function that } \\
\text { depends on aerosol type. } \\
\text { In this study, a value of } 1 \text { for } \gamma \text {. }\end{array}$ \\
\hline $\mathrm{ARVI} 2^{34}$ & Atmospherically resistant vegetation index 2 & $-0.18+1.17 *\left(\frac{\text { Band8-Band4 }}{\text { Band8+Band4 }}\right)$ \\
\hline \multirow[t]{2}{*}{ ATSAVI ${ }^{35}$} & $\begin{array}{l}\text { Adjusted transformed soil-adjusted } \\
\text { vegetation index }\end{array}$ & $\frac{a *(\text { Band8 }-a * \text { Band } 4-b)}{\text { Band } 8+B a n d 4-a b+X\left(1+a^{2}\right)}$ \\
\hline & & $a=1.22, b=0.03, X=0.08$ \\
\hline$A \mathrm{Al}^{36}$ & Ashburn vegetation index & $2 *$ Band $8 a-$ Band 4 \\
\hline $\mathrm{BNDVI}^{37}$ & Blue-normalized difference vegetation index & $($ Band8 - Band2)/(Band8 + Band2) \\
\hline $\mathrm{BR}^{38}$ & Browning reflectance index & $\frac{1 / \text { Band3-1/Band5 }}{\text { Band6 }}$ \\
\hline BWDRVI $^{39}$ & Blue-wide dynamic range vegetation index & $\frac{0.1 * \text { Band7-Band2 }}{0.1 * \text { Band7 }+ \text { Band2 }}$ \\
\hline \multirow[t]{3}{*}{$\mathrm{CARI}^{40}$} & Chlorophyll absorption ratio index & $\frac{\text { Band } 5 * \sqrt{(a * \text { Band4+Band4 }+b)^{2}}}{\text { Band4 }} *\left(a^{2}+1\right)^{0.5}$ \\
\hline & & $a=($ Band5 - Band3 $) / 150$ \\
\hline & & $b=$ Band $3 * 550 * a$ \\
\hline $\mathrm{CCCl}^{41}$ & Canopy chlorophyll content index & $\frac{\left(\frac{\text { Band8-Band5 }}{\text { Band8+Band5 }}\right)}{\left(\frac{\text { Band8-Band4 }}{\text { Band8+Band4 }}\right)}$ \\
\hline CRI550 42 & Carotenoid reflectance index 550 & $\frac{1}{\text { Band2 }}-\frac{1}{\text { Band3 }}$ \\
\hline $\mathrm{CRI} 700^{42}$ & Carotenoid reflectance index 700 & $\frac{1}{\text { Band2 }}-\frac{1}{\text { Band5 }}$ \\
\hline $\mathrm{CVI}^{43}$ & Chlorophyll vegetation index & $\frac{\text { Band8 } * \text { Band4 }}{(\text { Band3 })^{2}}$ \\
\hline Datt $1^{44}$ & Vegetation index proposed by Datt 1 & $\frac{\text { Band8-Band5 }}{\text { Band8-Band4 }}$ \\
\hline Datt2 $^{45}$ & Vegetation index proposed by Datt 2 & $\frac{\text { Band4 }}{\text { Band3*Band5 }}$ \\
\hline Datt3 ${ }^{45}$ & Vegetation index proposed by Datt 3 & $\frac{\text { Band8a }}{\text { Band3*Band5 }}$ \\
\hline $\mathrm{DVI}^{46}$ & Differenced vegetation index & $2.4 *$ Band $8-$ Band 4 \\
\hline EPIcar ${ }^{45}$ & Eucalyptus pigment index for carotenoid & $0.0049 *\left(\frac{\text { Band4 }}{\text { Band3*Band5 }}\right)^{0.7488}$ \\
\hline EPIChla $^{45}$ & Eucalyptus pigment index for chlorophyll a & $0.0161 *\left(\frac{\text { Band4 }}{\text { Band3*Band5 }}\right)^{0.7784}$ \\
\hline EPIChlab ${ }^{45}$ & Eucalyptus pigment index for chlorophyll $a+b$ & $0.0236 *\left(\frac{\text { Band4 }}{\text { Band3*Band5 }}\right)^{0.7954}$ \\
\hline EPIChlb $^{45}$ & Eucalyptus pigment index for chlorophyll b & $0.0337 *\left(\frac{\text { Band4 } 4}{\text { Band3 }}\right)^{1.8695}$ \\
\hline $\mathrm{EVI}^{14}$ & Enhanced vegetation index & $2.5 * \frac{\text { Band8-Band4 }}{\text { Band8 }+6 * \text { Band } 4-7.5 * \text { Band2 }+1}$ \\
\hline $\mathrm{EVI} 2^{47}$ & Enhanced vegetation index 2 & $2.4 * \frac{\text { Band8-Band4 }}{\text { Band8 }+ \text { Band } 4+1}$ \\
\hline $\mathrm{EVI} 2.2^{48}$ & Enhanced vegetation index 2.2 & $2.5 * \frac{\text { Band8-Band4 }}{\text { Band8 } 82.4 * \text { Band } 4+1}$ \\
\hline
\end{tabular}


Table 1 (Continued).

\begin{tabular}{|c|c|c|}
\hline Abbreviation & Index & Formula \\
\hline $\mathrm{GARI}^{49}$ & $\begin{array}{l}\text { Green atmospherically resistant } \\
\text { vegetation index }\end{array}$ & $\frac{\text { Band8-[Band3-(Band2-Band4)] }}{\text { Band8-[Band3+(Band2-Band4)] }}$ \\
\hline GBNDVI ${ }^{50}$ & $\begin{array}{l}\text { Green-Blue normalized difference } \\
\text { vegetation index }\end{array}$ & $\frac{\text { Band8-(Band3+Band2) }}{\text { Band8+(Band3+Band2) }}$ \\
\hline GDVI $^{51}$ & Green difference vegetation index & Band8 - Band3 \\
\hline \multirow[t]{2}{*}{ GEMI $^{52}$} & Global environment monitoring index & $\frac{n *(1-0.25 * n)-\text { Band } 4-0.125}{1-\text { Band } 4}$ \\
\hline & & $n=\frac{2 * \text { Band5 }^{2}-\text { Band }^{2}+1.5 * \text { Band } 5+0.5 * \text { Band }^{2}}{\text { Band5 }+ \text { Band } 4+0.5}$ \\
\hline $\mathrm{GLI}^{53}$ & Green leaf index & $\frac{2 * \text { Band3-Band5-Band2 }}{2 * \text { Band3+Band5 }+ \text { Band2 }}$ \\
\hline GNDVI ${ }^{49}$ & $\begin{array}{l}\text { Green normalized difference } \\
\text { vegetation index }\end{array}$ & $\frac{\text { Band8-Band3 }}{\text { Band8+Band3 }}$ \\
\hline GNDVI2 ${ }^{49}$ & $\begin{array}{l}\text { Green normalized difference } \\
\text { vegetation index } 2\end{array}$ & $\frac{\text { Band7-Band3 }}{\text { Band7 }+ \text { Band3 }}$ \\
\hline GOSAVI ${ }^{54}$ & $\begin{array}{l}\text { Green optimized soil-adjusted } \\
\text { vegetation index }\end{array}$ & $\frac{\text { Band8-Band3 }}{\text { Band8+Band } 3+0.16}$ \\
\hline GRNDVI $\left.\right|^{55}$ & $\begin{array}{l}\text { Green-red normalized difference } \\
\text { vegetation index }\end{array}$ & $\frac{\text { Band8-(Band3+Band5) }}{\text { Band8+(Band3+Band5) }}$ \\
\hline GVMI $^{56}$ & Global vegetation moisture index & $\frac{(\text { Band8 }+0.1)-(\text { Band12 }+0.02)}{(\text { Band8 }+0.1)+(\text { Band12 }+0.02)}$ \\
\hline $\mathrm{Hue}^{57}$ & Hue & $a \tan \left[\frac{2 * \text { Band5 }- \text { Band} 3-B a n d 2}{30.5} *(\right.$ Band3 $3-$ Band 2$)$ \\
\hline$|P V|^{58}$ & Infrared percentage vegetation index & $\frac{\frac{\text { Band8 }}{\text { Band8+tBand5 }}}{2}\left(\frac{\text { Band5-Band3 }}{\text { Band5 }+ \text { Band5 }}+1\right)$ \\
\hline $\mathrm{LCl}^{44}$ & Leaf chlorophyll index & $\frac{\text { Band8-Band5 }}{\text { Band8+Band4 }}$ \\
\hline Maccion $^{59}$ & Vegetation index proposed by Maccioni & $\begin{array}{l}\text { Band7-Band5 } \\
\text { Band7-Band4 }\end{array}$ \\
\hline $\mathrm{MCARI}^{60}$ & $\begin{array}{l}\text { Modified chlorophyll absorption in } \\
\text { reflectance index }\end{array}$ & $\begin{array}{l}{[(\text { Band5 }- \text { Band4 })-0.2 *} \\
(\text { Band5 }- \text { Band3 })] * \text { Band5 } \\
\text { Band4 }\end{array}$ \\
\hline MCARI/MTVI2 ${ }^{61}$ & MCARI/MTVI2 & MCARI/MTVI2 \\
\hline MCARI/OSAVI ${ }^{62}$ & MCARI/OSAVI & MCARI/OSAVI \\
\hline MCARI $1^{62}$ & $\begin{array}{l}\text { Modified chlorophyll absorption in } \\
\text { reflectance index } 1\end{array}$ & $\begin{array}{l}1.2 *[2.5 *(\text { Band8 }- \text { Band4 }) \\
-1.3 *(\text { Band8 }- \text { Band } 3)]\end{array}$ \\
\hline MCARI2 $^{62}$ & $\begin{array}{l}\text { Modified chlorophyll absorption in } \\
\text { reflectance index } 2\end{array}$ & $1.5 * \frac{2.5 *(\text { Band8-Band4 })-1.3 *(\text { Band8-Band } 3)}{\sqrt{(2 * \text { Bamd8 }+1)^{2}-(6 * \text { Band8-5* } \sqrt{\text { Band4 })-0.5}}}$ \\
\hline$M G V I^{63}$ & Green vegetation index proposed by Misra & $\begin{array}{c}-0.386 * \text { Band } 3-0.530 * \text { Band } 4+ \\
0.535 * \text { Band } 6+0.532 * \text { Band } 8\end{array}$ \\
\hline$m N D V I^{64}$ & $\begin{array}{l}\text { Modified normalized difference } \\
\text { vegetation index }\end{array}$ & $\frac{\text { Band8-Band4 }}{\text { Band8+Band4-2*Band2 }}$ \\
\hline $\mathrm{MNSI}^{63}$ & Non such index proposed by Misra & $\begin{array}{c}0.404 * \text { Band } 3+0.039 * \text { Band } 4- \\
0.505 * \text { Band6 }+0.762 * \text { Band } 8\end{array}$ \\
\hline MSAVI 65 & Modified soil-adjusted vegetation index & $\frac{2 * \text { Band } 8+1-\sqrt{(2 * \text { Band8 }+1)^{2}-8 *(\text { Band8-Band5) }}}{2}$ \\
\hline MSAVI2 ${ }^{65}$ & Modified soil-adjusted vegetation index 2 & $\frac{2 * \text { Band8 }+1-\sqrt{(2 * \text { Band8 }+1)^{2}-8 *(\text { Band8-Band4 })}}{2}$ \\
\hline $\mathrm{MSBI}^{63}$ & Soil brightness index proposed by Misra & $\begin{array}{c}0.406 * \text { Band } 3+0.600 * \text { Band } 4+ \\
0.645 * \text { Band } 6+0.243 * \text { Band } 8\end{array}$ \\
\hline
\end{tabular}


Sonobe et al.: Crop classification from Sentinel-2-derived vegetation indices...

Table 1 (Continued).

\begin{tabular}{|c|c|c|}
\hline Abbreviation & Index & Formula \\
\hline \multirow[t]{2}{*}{ MSR670 66} & \multirow[t]{2}{*}{ Modified simple ratio $670 / 800$} & $\frac{\text { Band8 }}{\text { Band4 }}-1$ \\
\hline & & $\sqrt{\frac{\text { Band8 }+1}{\text { Band4 }}}$ \\
\hline \multirow{2}{*}{ MSRNir/Red ${ }^{67}$} & \multirow{2}{*}{ Modified simple ratio NIR/red } & $\frac{\text { Band8 }}{\text { Band5 }}-1$ \\
\hline & & $\sqrt{\frac{\text { Band8 }}{\text { Band5 }}+1}$ \\
\hline$M T V I 2^{62}$ & Modified triangular vegetation index 2 & 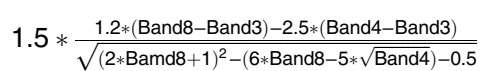 \\
\hline $\mathrm{NBR}^{68}$ & $\begin{array}{l}\text { Normalized difference NIR/SWIR } \\
\text { normalized burn ratio }\end{array}$ & $\frac{\text { Band8-Band12 }}{\text { Band8+Band12 }}$ \\
\hline ND774/677 69 & Normalized difference $774 / 677$ & $\frac{\text { Band7-Band4 }}{\text { Band7 }+ \text { Band4 }}$ \\
\hline NDII ${ }^{70}$ & Normalized difference infrared index & $\frac{\text { Band8-Band11 }}{\text { Band8+Band11 }}$ \\
\hline $\mathrm{NDRE}^{71}$ & Nnormalized difference red-edge & $\frac{\text { Band7-Band5 }}{\text { Band7+Band5 }}$ \\
\hline $\mathrm{NDSI}^{72}$ & Normalized difference salinity index & $\frac{\text { Band11-Band12 }}{\text { Band11+Band12 }}$ \\
\hline$N D V I^{12}$ & Normalized difference vegetation index & $\frac{\text { Band8-Band4 }}{\text { Band8+Band4 }}$ \\
\hline$N D V I 2^{51}$ & Normalized difference vegetation index 2 & $\frac{\text { Band12-Band8 }}{\text { Band12+Band8 }}$ \\
\hline NGRDI ${ }^{69}$ & Normalized green red difference index & $\frac{\text { Band3-Band5 }}{\text { Band3+Band5 }}$ \\
\hline OSAVI $I^{54,73}$ & Optimized soil-adjusted vegetation index & $1.16 * \frac{\text { Band8-Band4 }}{\text { Band8 }+ \text { Bandd } 4+0.16}$ \\
\hline $\mathrm{PNDVI}^{55}$ & Pan normalized difference vegetation index & $\frac{\text { Band8- }(\text { Band3 }+ \text { Band5 }+ \text { Band2 })}{\text { Band8 }+(\text { Band3 }+ \text { Band5+Band2 })}$ \\
\hline $\mathrm{PVR}^{74}$ & Photosynthetic vigor ratio & $\frac{\text { Band3-Band4 }}{\text { Band3+Band4 }}$ \\
\hline RBNDVI $^{55}$ & $\begin{array}{l}\text { Red-blue normalized difference } \\
\text { vegetation index }\end{array}$ & $\frac{\text { Band8-(Band4+Band2) }}{\text { Band8 }+(\text { Band4 }+ \text { Band2 })}$ \\
\hline $\mathrm{RDVI}^{75}$ & Renormalized difference vegetation index & $\frac{\text { Band8-Band4 }}{\sqrt{\text { Band8+Band4 }}}$ \\
\hline REIP 76 & Red-edge inflection point & $700+40 *\left[\frac{\left(\frac{\text { Band4 }+ \text { Band7 }}{2}\right)-\text { Band5 }}{\text { Band6-Band5 }}\right]$ \\
\hline $\mathrm{Rre}^{77}$ & Reflectance at the inflexion point & $\frac{\text { Band } 4+\text { Band7 }}{2}$ \\
\hline $\mathrm{SAVI} \mathrm{I}^{13}$ & Soil adjusted vegetation index & $1.5 * \frac{\text { Band8-Band } 4}{\text { Band8 } 8+\text { Band } 4+0.5}$ \\
\hline $\mathrm{SBL}^{46}$ & Soil background line & Band8 $-2.4 *$ Band4 \\
\hline $\mathrm{SIPI}^{78}$ & Structure intensive pigment index & $\frac{\text { Band8-Band2 }}{\text { Band8-Band4 }}$ \\
\hline SIWSI ${ }^{79}$ & Shortwave infrared water stress index & $\frac{\text { Band8a-Band11 }}{\text { Band8a+Band11 }}$ \\
\hline SLAVI ${ }^{80}$ & Specific leaf area vegetation index & $\frac{\text { Band8 }}{\text { Band4+Band12 }}$ \\
\hline $\mathrm{TCARI}^{60}$ & Transformed chlorophyll absorption ratio & $\begin{array}{c}3 *[(\text { Band5 }- \text { Band4 })-0.2 * \\
\left.(\text { Band5 }- \text { Band } 3)\left(\frac{\text { Band5 }}{\text { Band4 }}\right)\right]\end{array}$ \\
\hline TCARI/OSAVI ${ }^{73}$ & TCARI/OSAVI & TCARI/OSAVI \\
\hline $\mathrm{TCl}^{43,81}$ & Triangular chlorophyll index & $\begin{array}{c}1.2 *(\text { Band5 }- \text { Band3 })-1.5 * \\
\quad(\text { Band4 }- \text { Band3 }) * \sqrt{\frac{\text { Band5 }}{\text { Band4 }}}\end{array}$ \\
\hline $\mathrm{TVI}^{82}$ & Transformed vegetation index & $\sqrt{\mathrm{NDVI}+0.5}$ \\
\hline VARI700 83 & Visible atmospherically resistant index 700 & $\frac{\text { Band } 5-1.7 * \text { Band } 4+0.7 * \text { Band } 2}{\text { Band5 }+2.3 * \text { Band } 4-1.3 * \text { Band } 2}$ \\
\hline VARIgreen $^{83}$ & Visible atmospherically resistant index green & $\frac{\text { Band3-Band4 }}{\text { Band3+Band4-Band2 }}$ \\
\hline VI $700^{84}$ & Vegetation index 700 & $\frac{\text { Band5-Band4 }}{\text { Band5+Band4 }}$ \\
\hline WDRVI ${ }^{85}$ & Wide dynamic range vegetation index & $\frac{0.1 * \text { Band8-Band } 4}{0.1 * \text { Band8+Band } 4}$ \\
\hline
\end{tabular}


Table 2 Crop type and number of fields.

\begin{tabular}{lccc}
\hline \hline Crop type & Training data & Validation data & Test data \\
\hline Beans & 1132 & 566 & 567 \\
Beetroot & 774 & 387 & 387 \\
Grassland & 1055 & 527 & 528 \\
Maize & 500 & 250 & 250 \\
Potato & 1226 & 613 & 613 \\
Wheat & 1632 & 816 & 816 \\
\hline \hline
\end{tabular}

overfit. If it is too small, there may be underfitting. It controls the trade-off between errors of the SVM on training data and margin maximization $(C=\infty$ leads to hard margin SVM). The $\gamma$ value defines how far the influence of a single training example reaches, with low values meaning "far" and high values meaning "close."

$\mathrm{RF}$ is an ensemble learning technique composed of multiple decision trees based on random bootstrapped samples of the training data ${ }^{88}$ The output is determined by a majority vote of the results of decision trees. There are two user-defined hyperparameters including the number of trees ( $n$ tree) and the number of variables used to split the nodes ( $m$ try). If $n$ tree is made larger, the generalization error always converges, and over-training will not be a problem. On the other hand, a reduction in $m$ try makes each individual decision tree weaker.

The best combinations of these hyperparameters were determined using the Gaussian process, Bayesian optimization, ${ }^{89}$ which has been widely applied for hyperparameter tuning of machine learning algorithms. ${ }^{1}$

Ensemble machine learning methods have been used to obtain better predictive performance than from single learning algorithms, and the SL methodology has been proposed. ${ }^{90}$ In this method, given algorithms are combined through a convex weighted combination to minimize cross-validated errors. First, classification models based on RF or SVM were trained as the base algorithms using the training data. Next, a 10-fold cross validation was performed on each and the cross-validated predicted results were obtained. $N$ is the number of rows in the training data, cross-validated predicted results were combined, and an $N$ by two matrices was obtained as the "level-one" data and meta-learning model was generated. To predict the test data, the predictions from the base learners were fed into the metalearning model to generate the ensemble prediction. The data-based sensitivity analysis (DSA), ${ }^{91}$ which performs a pure black box use of the fitted models by querying the fitted models with sensitivity samples and recording their responses, was applied for assessing the sensitivity of the classification models.

\subsection{Accuracy Assessment}

Classification accuracies were evaluated based on the simple measures of quantity disagreement (QD) and allocation disagreement (AD). ${ }^{92}$ They provide an effective summary of confusion matrices. ${ }^{93}$

The proportion of fields that are classified as crop $i$ and their actual classes are crop $j\left(P_{i j}\right)$ is expressed in the following

$$
P_{i j}=W_{i} \frac{n_{i j}}{n_{i+}}
$$

where $W_{i}$ is the fields classified as crop $i, n_{i j}$ is the number of fields classified as crop $i$, and their actual classes are crop $j . n_{i+}$ is the row totals of the confusion matrix. In this case, AD and QD are calculated using the following:

$$
\mathrm{AD}_{i}=2 \min \left(p_{i+}, p_{+i}\right)-2 p_{i i}
$$




$$
\begin{aligned}
\mathrm{AD} & =\frac{1}{2} \sum_{i=1}^{N_{c}} A D_{i}, \\
\mathrm{QD}_{i} & =\left|p_{i+}-p_{+i}\right|, \\
\mathrm{QD} & =\frac{1}{2} \sum_{i=1}^{N_{c}} \mathrm{QD}_{i},
\end{aligned}
$$

where $N_{c}$ is the number of classes (six in this study), $p_{i+}$ and $p_{+i}$ are the row and column totals of the confusion matrix, $\mathrm{AD}_{i}$ is the allocation disagreement of crop $i$, and $\mathrm{QD}_{i}$ is the quantity disagreement of crop $i$, respectively. The sum of $\mathrm{QD}_{i}(\mathrm{QD})$ and $\mathrm{AD}_{i}(\mathrm{AD})$ are calculated and the total disagreement can be evaluated by the sum of $\mathrm{QD}$ and $\mathrm{AD} .{ }^{92}$

In addition, three indicators including overall accuracy [OA, Eq. (6)], producer's accuracy [PA, Eq. (7)], and user's accuracy [UA, Eq. (8)] were calculated because they have widely been applied for assessing classification accuracies

$$
\begin{gathered}
\mathrm{OA}=\sum_{i=1}^{N} p_{i i} / N, \\
\mathrm{PA}=p_{i i} / R_{i}, \\
\mathrm{UA}=p_{i i} / C_{i},
\end{gathered}
$$

where $N$ is the number of fields, $R_{i}$ and $C_{i}$ represent the total number of crop $i$ in the correct data and the total number from the classification results, respectively. McNemar's test ${ }^{94}$ has been used to judge whether the differences between two given classification results were significant, ${ }^{95}$ and it was also applied in this study.

\section{Results and Discussion}

\subsection{Classification Accuracy}

Crop classification maps are shown in Fig. 2, the maximum, minimum, and averaged accuracies of 10 repetitions and confusion matrices when all the repetitions were merged are shown in Tables 3 and 4. Averaged OAs were $89.0 \%$ for RF, 90.6\% for SVM, and $91.6 \%$ for the ensemble machine learning method and the mean PAs and mean UAs derived using the machine learning algorithms were $>0.8$, excepting those of RF (mean UA for maize was 0.797). All machine learning algorithms performed well in classifying croplands. Especially, the good accuracies were confirmed for the PAs and UAs for wheat $(>93.8 \%)$ and beet $(>89.9 \%)$. However, the chi-square values based on McNemar's tests were 12.02 to $40.60,27.78$ to 62.43 , and 17.00 to 51.60 for R-SVM, RF-SL, and SVM-SL, respectively. As a result, significant differences were confirmed among the results of three machine learning algorithms $(p<0.05)$.

Classification results by SL had the best OA and AD + QD (8.5\%) and SVM had a slightly better PA of wheat $(97.1 \%)$. On the contrary, identifying maize fields was difficult due to the similarity in their reflectance. Grasses cultivation employs fewer controls and then a lot of weeds were mixed with timothy and orchard grass in grasslands. As a result, variation in reflectance features was larger than in other crop types, causing misclassifications of relatively large fields.

Figure 3 shows the relationship between field area and misclassified fields for each algorithm after 10 repetitions (i.e., the total number is 10 times of that of the test data). More than $75 \%$ of the misclassified fields were $<200 \mathrm{a}$ in area for all algorithms, and $95.1 \%$ (RF), 95.5\% (SVM), and $96.1 \%$ (SL) of misclassified fields were below 450 a. Applying stacking made the model more robust for classifying smaller fields and the number of misclassified croplands decreased 

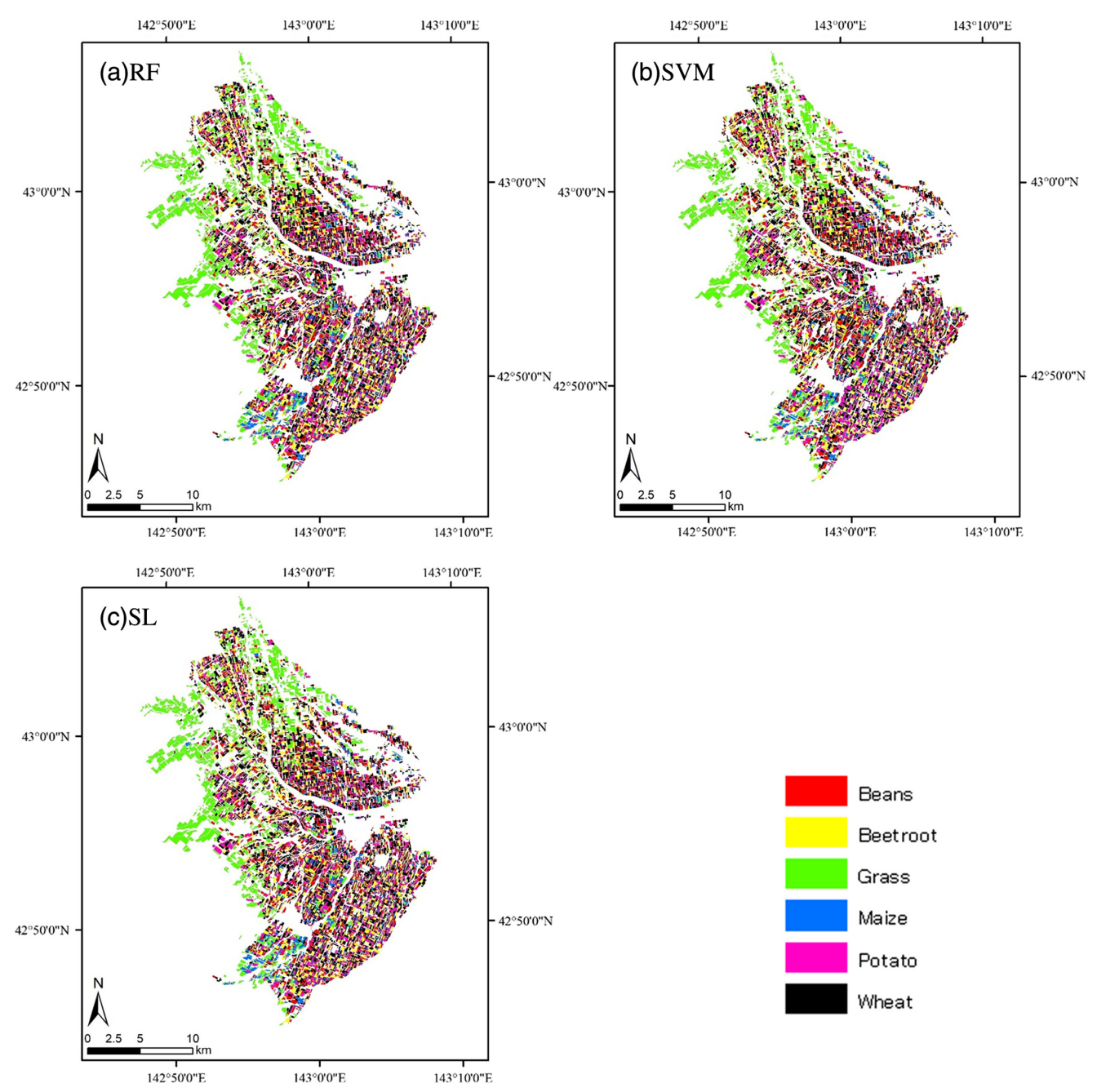

Fig. 2 Crop classification map generated by (a) RF, (b) SVM, and (c) SL.

(813 fields for smaller than 50 a) compared with the results by RF (909 fields for smaller than 50 a) and SVM (855 fields for smaller than 50 a). It was especially useful for identifying beans fields. It was not effective for identifying small grasslands as grass cultivation employs fewer controls and many weeds were present in grasslands. However, stacking was useful for identifying grasslands more than 500 a, which had a certain homogeneity with Dactylis glomerata or Phleum pretense in the MSI image.

\subsection{Sensitive Factor Analysis}

Reflectance values obtained from Sentinel-2A are shown in Fig. 4. Differences in reflectance were particularly clear between wheat and beans as the wheat harvest was finished on 11 August and the reflectance of wheat fields was similar to that of bare soil. Beetroot had the steepest gradient between bands 5 and 6 and some differences in the reflectance values at band 11 were confirmed between maize and potato. Differences in the reflectance patterns between grass and beans were not clear.

To clarify which variables contributed to identifying each crop type, DSA was conducted for each algorithm and their importance values were calculated.

For identifying beans fields, Datt3 $(6.0 \%, 6.6 \%$, and $6.3 \%$ for RF, SVM, and SL, respectively) and REIP (6.4\%, 8.2\%, and 7.3\% for RF, SVM, and SL, respectively) played important roles in the three algorithms. Some variables (the reflectance values at bands 2 and 3, AFRI2.1, CVI and NDSI) possessed importance values of $>5.0 \%$ in the RF-based model, whereas no 
Table 3 Classification accuracies of each algorithm.

\begin{tabular}{|c|c|c|c|c|c|c|c|c|c|}
\hline & \multicolumn{3}{|c|}{ RF } & \multicolumn{3}{|c|}{ SVM } & \multicolumn{3}{|c|}{ SL } \\
\hline & $\begin{array}{l}\text { Minimum } \\
(\%)\end{array}$ & $\begin{array}{l}\text { Maximum } \\
(\%)\end{array}$ & $\begin{array}{l}\text { Mean } \pm \\
\text { std }(\%)\end{array}$ & $\begin{array}{l}\text { Minimum } \\
(\%)\end{array}$ & $\begin{array}{l}\text { Maximum } \\
(\%)\end{array}$ & $\begin{array}{l}\text { Mean } \pm \\
\text { std (\%) }\end{array}$ & $\begin{array}{c}\text { Minimum } \\
(\%)\end{array}$ & $\begin{array}{l}\text { Maximum } \\
(\%)\end{array}$ & $\begin{array}{l}\text { Mean } \pm \\
\text { std (\%) }\end{array}$ \\
\hline \multicolumn{10}{|l|}{ PA } \\
\hline Beans & 80.6 & 86.4 & $83.4 \pm 1.6$ & 81.1 & 90.5 & $86.2 \pm 2.2$ & 84.7 & 90.3 & $87.6 \pm 1.4$ \\
\hline Beet & 89.9 & 94.8 & $93.0 \pm 1.3$ & 91.0 & 96.4 & $94.5 \pm 1.5$ & 93.8 & 96.1 & $95.1 \pm 0.6$ \\
\hline Grassland & 84.3 & 88.3 & $86.0 \pm 1.2$ & 86.7 & 93.8 & $89.4 \pm 2.5$ & 89.8 & 94.3 & $92.1 \pm 1.4$ \\
\hline Maize & 78.8 & 84.8 & $80.8 \pm 1.7$ & 78.8 & 87.6 & $83.0 \pm 3.1$ & 81.2 & 87.6 & $84.6 \pm 1.8$ \\
\hline Potato & 82.9 & 89.7 & $87.0 \pm 1.8$ & 83.5 & 89.9 & $87.6 \pm 1.9$ & 84.0 & 89.7 & $88.1 \pm 1.6$ \\
\hline Wheat & 96.4 & 97.9 & $97.0 \pm 0.5$ & 96.3 & 97.5 & $97.1 \pm 0.4$ & 95.7 & 97.5 & $97.0 \pm 0.7$ \\
\hline \multicolumn{10}{|l|}{ UA } \\
\hline Beans & 84.9 & 88.6 & $86.8 \pm 1.1$ & 82.0 & 91.4 & $86.4 \pm 2.9$ & 83.4 & 90.3 & $88.6 \pm 2.0$ \\
\hline Beet & 94.5 & 96.9 & $95.6 \pm 0.8$ & 94.3 & 97.3 & $95.7 \pm 0.9$ & 95.1 & 97.1 & $96.0 \pm 0.6$ \\
\hline Grassland & 88.0 & 93.3 & $91.0 \pm 1.4$ & 89.9 & 96.6 & $94.0 \pm 2.3$ & 93.8 & 97.7 & $95.7 \pm 1.1$ \\
\hline Maize & 77.8 & 82.0 & $79.7 \pm 1.3$ & 78.4 & 87.3 & $81.9 \pm 2.2$ & 81.4 & 85.2 & $83.6 \pm 1.4$ \\
\hline Potato & 78.5 & 83.1 & $81.5 \pm 1.2$ & 82.1 & 87.8 & $85.2 \pm 1.9$ & 83.0 & 86.8 & $85.4 \pm 1.1$ \\
\hline Wheat & 93.8 & 96.1 & $95.0 \pm 0.7$ & 94.5 & 97.2 & $95.9 \pm 0.8$ & 95.1 & 97.2 & $96.2 \pm 0.6$ \\
\hline $\mathrm{OA}$ & 88.5 & 89.4 & $89.0 \pm 0.2$ & 89.3 & 92.0 & $90.6 \pm 0.9$ & 90.2 & 92.2 & $91.6 \pm 0.6$ \\
\hline$\kappa$ & 85.9 & 87.0 & $86.5 \pm 0.3$ & 86.8 & 90.2 & $88.4 \pm 1.1$ & 88.0 & 90.5 & $89.6 \pm 0.8$ \\
\hline$A D$ & 8.0 & 9.9 & $9.0 \pm 0.6$ & 6.5 & 9.7 & $7.9 \pm 1.0$ & 6.5 & 8.8 & $7.3 \pm 0.7$ \\
\hline QD & 1.3 & 2.8 & $2.0 \pm 0.5$ & 0.7 & 2.5 & $1.5 \pm 0.6$ & 0.6 & 2.3 & $1.2 \pm 0.5$ \\
\hline
\end{tabular}

variables except for Datt3 and REIP had importance values of $>5.0 \%$ for SVM and SL. Even though the importance values of GEMI, Maccioni, and MNSI in SVM were $<5.0 \%$, they were more than five times those in RF. AFRI1.6 and SIWSI were useful for identifying beetroot fields and AFRI1.6 occupied $11.1 \%, 6.8 \%$, and $9.0 \%$ and SIWSI occupied $10.6 \%, 7.1 \%$, and $8.9 \%$ of the importance for RF, SVM, and SL, respectively. GEMI and NDSI also had importance values of $>10 \%$ for RF, but were $<5 \%$ for the others. In contrast, REIP was useful in SVM and it occupied 9.1\% of the importance in SVM. AFRI1.6, REIP, and MNSI were effective for identifying grassland for all algorithms, whereas SIWSI played an important role (7.8\%) for RF and the reflectance at band 6 played an important role (8.2\%) for SVM. For identifying maize fields, no variable had importance values $>5.0 \%$ for any algorithm, but the importance value of REIP was $25.3 \%$ for SVM (2.9\% for RF). CRI550, CRI700, and MSBI were 9.1\%, 12.9\%, and 5.6\% in RF, respectively (those in SVM were $2.4 \%, 2.2 \%$, and $3.6 \%$, respectively). REIP played the greatest role for identifying potato fields in all algorithms (12.8\%, 6.9\% and 9.9\% for RF, SVM, and SL, respectively). The importance values of CCCI and CVI were also high in RF (9.9\%) but those in SVM were $<3.0 \%$. In contrast, Maccioni had an importance of $6.9 \%$ in SVM but in RF was $1.4 \%$. REIP also played a great role for identifying wheat fields in SVM, but $1.2 \%$ of the importance value was confirmed in RF while AVI occupied $15.1 \%$ in RF (1.2\% in SVM). However, the original reflectance values possessed importance values of $<1.0 \%$.

In this season, the photosynthetic activities of each crop type were different; maize is a C4 plant, beans and beetroot were in their growing season, grassland was after second harvest, potato growth was inhibited by chemicals for easy harvesting, and wheat fields were cultivated. 
Sonobe et al.: Crop classification from Sentinel-2-derived vegetation indices...

Table 4 Confusion matrices for (a) RF, (b) SVM, and (c) SL.

\begin{tabular}{|c|c|c|c|c|c|c|c|}
\hline & & \multicolumn{6}{|c|}{ Reference data } \\
\hline & & Beans & Beetroot & Grasslands & Maize & Potato & Wheat \\
\hline \multicolumn{8}{|c|}{ (a) RF } \\
\hline \multirow[t]{6}{*}{ Classified data } & Beans & 4726 & 59 & 247 & 100 & 287 & 26 \\
\hline & Beet & 48 & 3599 & 23 & 28 & 65 & 1 \\
\hline & Grasslands & 172 & 65 & 4543 & 52 & 116 & 43 \\
\hline & Maize & 139 & 21 & 128 & 2019 & 177 & 48 \\
\hline & Potato & 503 & 119 & 230 & 235 & 5332 & 123 \\
\hline & Wheat & 82 & 7 & 109 & 66 & 153 & 7919 \\
\hline \multicolumn{8}{|c|}{ (b) SVM } \\
\hline \multirow[t]{6}{*}{ Classified data } & Beans & 4888 & 77 & 212 & 119 & 333 & 34 \\
\hline & Beet & 61 & 3659 & 17 & 22 & 63 & 2 \\
\hline & Grasslands & 110 & 34 & 4720 & 40 & 70 & 49 \\
\hline & Maize & 112 & 14 & 130 & 2076 & 166 & 40 \\
\hline & Potato & 429 & 79 & 121 & 189 & 5368 & 115 \\
\hline & Wheat & 70 & 7 & 80 & 54 & 130 & 7920 \\
\hline \multicolumn{8}{|c|}{ (c) SL } \\
\hline \multirow[t]{6}{*}{ Classified data } & Beans & 4965 & 82 & 105 & 83 & 333 & 42 \\
\hline & Beet & 61 & 3680 & 11 & 17 & 61 & 3 \\
\hline & Grasslands & 59 & 17 & 4861 & 37 & 52 & 53 \\
\hline & Maize & 85 & 8 & 121 & 2114 & 169 & 32 \\
\hline & Potato & 426 & 77 & 113 & 200 & 5403 & 112 \\
\hline & Wheat & 74 & 6 & 69 & 49 & 112 & 7918 \\
\hline
\end{tabular}

(a)

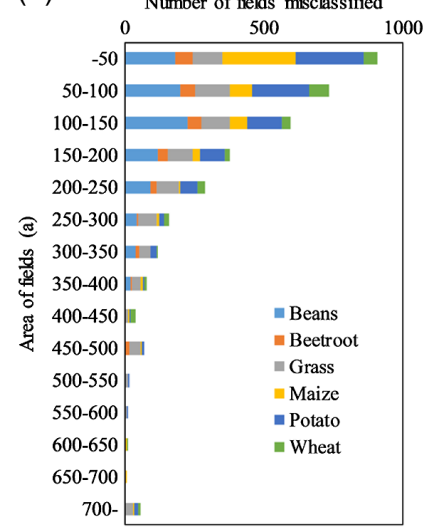

(b)

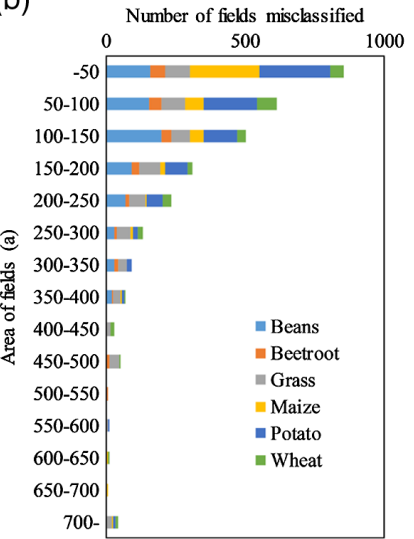

(c)

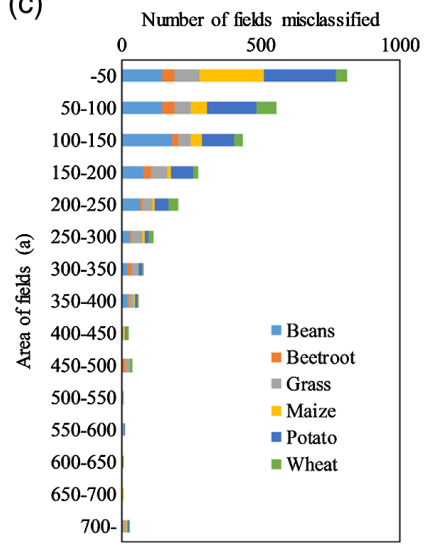

Fig. 3 Relationship between field area and misclassified fields (a) RF, (b) SVM, and (c) SL. 


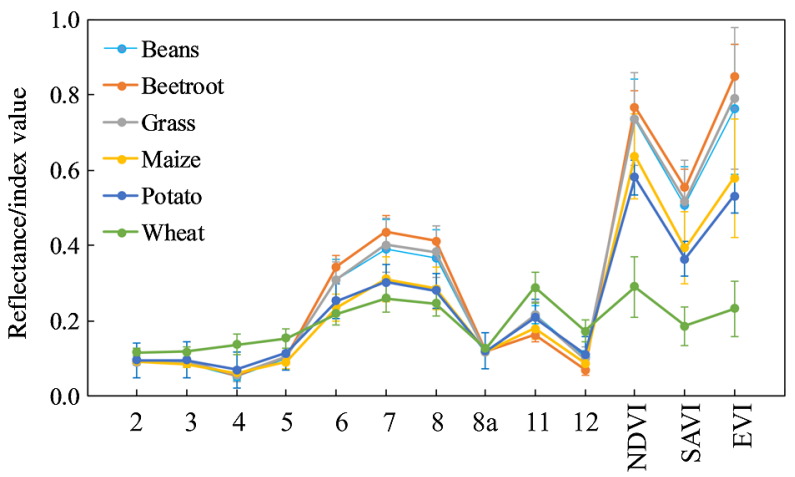

Fig. 4 Mean reflectance spectra and standard deviations of each crop.

In addition to indices related to chlorophyll content, the additional use of shortwave infrared data contributed to the estimation of photosynthetic pigments, water, nitrogen, cellulose, lignin, phenols, and leaf mass per area (e.g., NDSI). As a result, vegetation indices had greater influence on the classification results than the original reflectance. However, there were differences among algorithms in which vegetation indices were more important. The importance values in SL were near the averaged values of RF and SVM. So, the differences in importance between RF and SVM were useful when stacking was applied, and the modification contributed to identifying croplands with higher accuracies.

\section{Conclusions and Future Work}

Cropland classifications were conducted using a single image from Sentinel-2 MSI and the suitability and accuracy of vegetation indices from the original reflectance data from Sentinel-2 MSI were assessed.

Of the two algorithms applied (RF and SVM), the accuracy of SVM was superior and 89.3\% to $92.0 \%$ of OAs were confirmed. Furthermore, stacking contributed to higher OAs (90.2\% to 92.2\%) and significant differences were confirmed with the results of SVM. Based on DSA, the vegetation indices calculated from the original reflectance from Sentinel-2 MSI data were useful to identify the specific crop types. Although the vegetation indices that played the largest roles were different between RF and SVM, stacking helped to modify and reduce the importance of specific variables, which might prevent overfitting. Stacking should be utilized to monitor agricultural fields for improving classification accuracies.

The field is used as a basic unit in classification and some problems related to the borders of fields remain to be resolved. We are planning to evaluate the potential of geographic object-based image analysis in conjunction with MSI data and address this question in future work.

\section{Disclosures}

No potential conflicts of interest are reported by the authors.

\section{Acknowledgments}

The authors would like to thank Tokachi Nosai for providing the field data.

\section{References}

1. R. Sonobe et al., "Assessing the suitability of data from Sentinel-1A and 2A for crop classification," GISci. Remote Sens. 54, 918-938 (2017).

2. R. Sonobe et al., "Estimating leaf carotenoid contents of shade grown tea using hyperspectral indices and PROSPECT-D inversion," Int. J. Remote Sens. 39, 1306-1320 (2018).

3. C. Rankine et al., "Comparing MODIS and near-surface vegetation indexes for monitoring tropical dry forest phenology along a successional gradient using optical phenology towers," Environ. Res. Lett. 12, 105007 (2017). 
4. S. S. Liu et al., "Regional-scale winter wheat phenology monitoring using multisensor spatio-temporal fusion in a South Central China growing area," J. Appl. Remote Sens. 10, 046029 (2016).

5. J. Vithanage, S. N. Miller, and K. Driese, "Land cover characterization for a watershed in Kenya using MODIS data and Fourier algorithms," J. Appl. Remote Sens. 10, 045015 (2016).

6. R. Sonobe et al., "Evaluating metrics derived from Landsat 8 OLI imagery to map crop cover," Geocarto Int. (2018).

7. G. P. Asner, "Biophysical and biochemical sources of variability in canopy reflectance," Remote Sens. Environ. 64, 234-253 (1998).

8. M. A. Pena, R. Liao, and A. Brenning, "Using spectrotemporal indices to improve the fruit-tree crop classification accuracy," ISPRS J. Photogramm. Remote Sens. 128, 158-169 (2017).

9. D. Bankestad and T. Wik, "Growth tracking of basil by proximal remote sensing of chlorophyll fluorescence in growth chamber and greenhouse environments," Comput. Electron. Agric. 128, 77-86 (2016).

10. Z. Wang et al., "Spatiotemporal variations of forest phenology in the Qinling Mountains and its response to a critical temperature of 10 degrees C," J. Appl. Remote Sens. 12, 022202 (2018).

11. M. Morin et al., "Agreement analysis and spatial sensitivity of multispectral and hyperspectral sensors in detecting vegetation stress at management scales," J. Appl. Remote Sens. 11, 046025 (2017).

12. C. J. Tucker, "Red and photographic infrared linear combinations for monitoring vegetation," Remote Sens. Environ. 8, 127-150 (1979).

13. A. R. Huete, "A soil-adjusted vegetation index (SAVI)," Remote Sens. Environ. 25, 295-309 (1988).

14. A. Huete et al., "Overview of the radiometric and biophysical performance of the MODIS vegetation indices," Remote Sens. Environ. 83, 195-213 (2002).

15. C. E. Holden and C. E. Woodcock, "An analysis of Landsat 7 and Landsat 8 underflight data and the implications for time series investigations," Remote Sens. Environ. 185, 16-36 (2016).

16. M. Belgiu and O. Csillik, "Sentinel-2 cropland mapping using pixel-based and object-based time-weighted dynamic time warping analysis," Remote Sens. Environ. 204, 509-523 (2018).

17. M. Immitzer, F. Vuolo, and C. Atzberger, "First experience with Sentinel-2 data for crop and tree species classifications in Central Europe," Remote Sens. 8, 166 (2016).

18. Y. Palchowdhuri et al., "Classification of multi-temporal spectral indices for crop type mapping: a case study in Coalville, UK," J. Agric. Sci. 156, 24-36 (2018).

19. A. Novelli et al., "Performance evaluation of object based greenhouse detection from Sentinel-2 MSI and Landsat 8 OLI data: a case study from Almeria (Spain)," Int. J. Appl. Earth Obs. Geoinf. 52, 403-411 (2016).

20. Y. Du et al., "Water Bodies' mapping from Sentinel-2 imagery with modified normalized difference water index at 10-m spatial resolution produced by sharpening the SWIR Band," Remote Sens. 8, 354 (2016).

21. G. Biau and E. Scornet, "A random forest guided tour," Test 25, 197-227 (2016).

22. S. Ferrant et al., "Detection of irrigated crops from Sentinel-1 and Sentinel-2 data to estimate seasonal groundwater use in South India," Remote Sens. 9, 1119 (2017).

23. A. O. Onojeghuo et al., "Mapping paddy rice fields by applying machine learning algorithms to multi-temporal Sentinel-1A and Landsat data," Int. J. Remote Sens. 39, 1042-1067 (2018).

24. R. Sonobe et al., "Discrimination of crop types with TerraSAR-X-derived information," Phys. Chem. Earth. Parts A, B, C 83-84, 2-13 (2015).

25. J. K. Gilbertson and A. van Niekerk, "Value of dimensionality reduction for crop differentiation with multi-temporal imagery and machine learning," Comput. Electron. Agric. 142, 50-58 (2017). 
26. R. Sonobe et al., "Random forest classification of crop type using multi- temporal TerraSAR- X dual- polarimetric data," Remote Sens. Lett. 5, 157-164 (2014).

27. G. Camps-Valls et al., "Robust support vector method for hyperspectral data classification and knowledge discovery," IEEE Trans. Geosci. Remote Sens. 42, 1530-1542 (2004).

28. M. Drusch et al., "Sentinel-2: ESA's optical high-resolution mission for GMES operational services," Remote Sens. Environ. 120, 25-36 (2012).

29. U.S. Geological Survey, "EarthExplorer," https://earthexplorer.usgs.gov/ (14 December 2016).

30. A. Chatziantoniou, G. P. Petropoulos, and E. Psomiadis, "Co-orbital Sentinel 1 and 2 for LULC mapping with emphasis on Wetlands in a Mediterranean setting based on machine learning," Remote Sens. 9, 1259 (2017).

31. E. M. D. Silveira et al., "Assessment of geostatistical features for object-based image classification of contrasted landscape vegetation cover," J. Appl. Remote Sens. 11, 036004 (2017).

32. A. Karnieli et al., "AFRI-aerosol free vegetation index," Remote Sens. Environ. 77, 10-21 (2001).

33. A. A. Gitelson, O. B. Chivkunova, and M. N. Merzlyak, "Nondestructive estimation of anthocyanins and chlorophylls in anthocyanic leaves," Am. J. Bot. 96, 1861-1868 (2009).

34. Y. J. Kaufman and D. Tanre, "Atmospherically resistant vegetation index (ARVI) for EOS-MODIS," IEEE Trans. Geosci. Remote Sens. 30, 261-270 (1992).

35. F. Baret and G. Guyot, "Potentials and limits of vegetation indices for LAI and APAR assessment," Remote Sens. Environ. 35, 161-173 (1991).

36. P. Ashburn, "The vegetative index number and crop identification," in The LACIE Symp. Proc. of the Technical Session, pp. 843-855 (1978).

37. C. G. Yang, J. H. Everitt, and J. M. Bradford, "Airborne hyperspectral imagery and linear spectral unmixing for mapping variation in crop yield," Precis. Agric. 8, 279-296 (2007).

38. O. B. Chivkunova et al., "Reflectance spectral features and detection of superficial scald -induced browning in storing apple fruit," J. Russ. Phytopathol. Soc. 2, 73-77 (2001).

39. D. W. Hancock and C. T. Dougherty, "Relationships between blue- and red-based vegetation indices and leaf area and yield of alfalfa," Crop Sci. 47, 2547-2556 (2007).

40. M. S. Kim et al., "The use of high spectral resolution bands for estimating absorbed photosynthetically active radiation (A par)," in The 6th Int. Symp. on Physical Measurements and Signatures in Remote Sensing, Val D'Isere, France (1994).

41. D. M. El-Shikha et al., "Remote sensing of cotton nitrogen status using the Canopy Chlorophyll Content Index (CCCI)," Trans. ASABE 51, 73-82 (2008).

42. A. A. Gitelson, M. N. Merzlyak, and O. B. Chivkunova, "Optical properties and nondestructive estimation of anthocyanin content in plant leaves," Photochem. Photobiol. 74, 38-45 (2001).

43. E. R. Hunt et al., "Remote sensing leaf chlorophyll content using a visible band index," Agron. J. 103, 1090-1099 (2011).

44. B. Datt, "Remote sensing of water content in eucalyptus leaves," Aust. J. Bot. 47, 909-923 (1999).

45. B. Datt, "Remote sensing of chlorophyll a, chlorophyll b, chlorophyll $\mathrm{a}+\mathrm{b}$, and total carotenoid content in eucalyptus leaves," Remote Sens. Environ. 66, 111-121 (1998).

46. A. J. Richardson and C. L. Wiegand, "Distinguishing vegetation from soil background information," Photogramm. Eng. Remote Sens. 43, 1541-1552 (1977).

47. T. Miura et al., "Inter-comparison of ASTER and MODIS surface reflectance and vegetation index products for synergistic applications to natural resource monitoring," Sensors 8, 2480-2499 (2008).

48. Z. Y. Jiang et al., "Development of a two-band enhanced vegetation index without a blue band," Remote Sens. Environ. 112, 3833-3845 (2008).

49. A. A. Gitelson, Y. J. Kaufman, and M. N. Merzlyak, "Use of a green channel in remote sensing of global vegetation from EOS-MODIS," Remote Sens. Environ. 58, 289-298 (1996). 
50. F. M. Wang, J. F. Huang, and L. Chen, "Development of a vegetation index for estimation of leaf area index based on simulation modeling," J. Plant Nutr. 33, 328-338 (2010).

51. C. J. Tucker, "Monitoring corn and soybean crop development with hand-held radiometer spectral data," Remote Sens. Environ. 8, 237-248 (1979).

52. B. Pinty and M. M. Verstraete, "GEMI: a non-linear index to monitor global vegetation from satellites," Vegetatio 101, 15-20 (1992).

53. N. Gobron et al., "Advanced vegetation indices optimized for up-coming sensors: design, performance, and applications," IEEE Trans. Geosci. Remote Sens. 38, 2489-2505 (2000).

54. G. Rondeaux, M. Steven, and F. Baret, "Optimization of soil-adjusted vegetation indices," Remote Sens. Environ. 55, 95-107 (1996).

55. F.-M. Wang et al., "New vegetation index and its application in estimating leaf area index of rice," Rice Sci. 14, 195-203 (2007).

56. E. P. Glenn, P. L. Nagler, and A. R. Huete, "Vegetation index methods for estimating evapotranspiration by remote sensing," Surv. Geophys. 31, 531-555 (2010).

57. R. Escadafal, A. Belghith, and H. Ben-Moussa, "Indices spectraux pour la degradation des milieux naturels en Tunisie aride," in 6e Symp. Int. sur les mesures physiques et signatures en teledetection, Val d'Isere, France, pp. 253-259 (1994)

58. R. E. Crippen, "Calculating the vegetation index faster," Remote Sens. Environ. 34, 71-73 (1990).

59. A. Maccioni, G. Agati, and P. Mazzinghi, "New vegetation indices for remote measurement of chlorophylls based on leaf directional reflectance spectra," J. Photochem. Photobiol. B 61, 52-61 (2001).

60. C. S. T. Daughtry et al., "Estimating corn leaf chlorophyll concentration from leaf and canopy reflectance," Remote Sens. Environ. 74, 229-239 (2000).

61. J. U. H. Eitel et al., "Using in-situ measurements to evaluate the new RapidEye (TM) satellite series for prediction of wheat nitrogen status," Int. J. Remote Sens. 28, 4183-4190 (2007).

62. D. Haboudane et al., "Hyperspectral vegetation indices and novel algorithms for predicting green LAI of crop canopies: modeling and validation in the context of precision agriculture," Remote Sens. Environ. 90, 337-352 (2004).

63. P. N. Misra, S. G. Wheeler, and R. E. Oliver, "Kauth-Thomas brigthness and greenness axes," Contract NASA 9-14350, pp. 23-46 (1977).

64. R. Main et al., "An investigation into robust spectral indices for leaf chlorophyll estimation," ISPRS J. Photogramm. Remote Sens. 66, 751-761 (2011).

65. J. Qi et al., "A modified soil adjusted vegetation index," Remote Sens. Environ. 48, 119-126 (1994).

66. J. M. Chen, "Evaluation of vegetation indices and a modified simple ratio for boreal applications," Can. J. Remote Sens. 22, 229-242 (1996).

67. J. M. Chen and J. Cihlar, "Retrieving leaf area index of boreal conifer forests using Landsat TM images," Remote Sens. Environ. 55, 153-162 (1996).

68. C. Key and N. Benson, Landscape assessment: ground measure of severity; the composite burn index, and remote sensing of severity, the normalized burn index and remote sensing of severity, the normalized burn ratio, in FIREMON: Fire Effects Monitoring and Inventory System, D. Lutes et al., Eds., pp. 1-51, Rocky Mountains Research Station, USDA Forest Service, Fort Collins, Colorado (2005).

69. P. J. Zarco-Tejada et al., "Scaling-up and model inversion methods with narrowband optical indices for chlorophyll content estimation in closed forest canopies with hyperspectral data," IEEE Trans. Geosci. Remote Sens. 39, 1491-1507 (2001).

70. M. A. Hardisky, V. Klemas, and R. M. Smart, "The influences of soil salinity, growth form, and leaf moisture on the spectral reflectance of Spartina Alterniflora canopies," Photogramm. Eng. Remote Sens. 49, 77-84 (1983).

71. E. M. Barnes et al., "Coincident detection of crop water stress, nitrogen status and canopy density using ground based multispectral data," in Proc. of Fifth Int. Conf. on Precision Agriculture and Other Resource Management ASA-CSSA-SSSA, Madison, USA (2000). 
72. A. Dehni and M. Lounis, "Remote sensing tetchniques for salt affected soil mapping: application to the Oran Region of Algeria," Procedia Eng. 33, 188-198 (2012).

73. D. Haboudane et al., "Integrated narrow-band vegetation indices for prediction of crop chlorophyll content for application to precision agriculture," Remote Sens. Environ. 81, 416-426 (2002).

74. G. Metternicht, "Vegetation indices derived from high-resolution airborne videography for precision crop management," Int. J. Remote Sens. 24, 2855-2877 (2003).

75. N. H. Broge and E. Leblanc, "Comparing prediction power and stability of broadband and hyperspectral vegetation indices for estimation of green leaf area index and canopy chlorophyll density," Remote Sens. Environ. 76, 156-172 (2001).

76. I. Herrmann et al., "LAI assessment of wheat and potato crops by VEN mu S and Sentinel-2 bands," Remote Sens. Environ. 115, 2141-2151 (2011).

77. J. Clevers et al., "Derivation of the red edge index using the MERIS standard band setting," Int. J. Remote Sens. 23, 3169-3184 (2002).

78. J. Penuelas, F. Baret, and I. Filella, "Semi-empirical indices to assess Carotenoids/ Chlorophyll-a ratio from leaf spectral reflectance," Photosynthetica 31, 221-230 (1995).

79. R. Fensholt and I. Sandholt, "Derivation of a shortwave infrared water stress index from MODIS near- and shortwave infrared data in a semiarid environment," Remote Sens. Environ. 87, 111-121 (2003).

80. L. Lymburner, P. J. Beggs, and C. R. Jacobson, "Estimation of canopy-average surfacespecific leaf area using Landsat TM data," Photogramm. Eng. Remote Sens. 66, 183-191 (2000).

81. D. Haboudane et al., "Remote estimation of crop chlorophyll content using spectral indices derived from hyperspectral data," IEEE Trans. Geosci. Remote Sens. 46, 423-437 (2008).

82. J. W. Rouse et al., "Monitoring vegetation systems in the great plains with ERTS," in Third Earth Resources Technology Satellite-1 Symp., S. C. Freden, E. P. Mercanti, and M. A. Becker, Eds., pp. 309-317, NASA, Washington, D.C (1974).

83. A. A. Gitelson et al., "Non-destructive and remote sensing techniques for estimation of vegetation status," in Third European Conf. on Precision Agriculture, Montpellier, France, pp. 301-306 (2001).

84. A. A. Gitelson et al., "Novel algorithms for remote estimation of vegetation fraction," Remote Sens. Environ. 80, 76-87 (2002).

85. A. A. Gitelson, "Wide dynamic range vegetation index for remote quantification of biophysical characteristics of vegetation," J. Plant Physiol. 161, 165-173 (2004).

86. T. Hastie, R. Tibshirani, and J. Friedman, The Elements of Statistical Learning: Data Mining, Inference, and Prediction, 2nd ed., Springer-Verlag, New York (2009)

87. C. Cortes and V. Vapnik, "Support-vector networks," Mach. Learn. 20, 273-297 (1995).

88. L. Breiman, "Random forests," Mach. Learn. 45, 5-32 (2001).

89. J. Bergstra and Y. Bengio, "Random search for hyper-parameter optimization," J. Mach. Learn. Res. 13, 281-305 (2012).

90. M. J. van der Laan, E. C. Polley, and A. E. Hubbard, "Super learner," Stat. Appl. Genet. Mol. Biol. 6, 1-23 (2007).

91. P. Cortez and M. J. Embrechts, "Using sensitivity analysis and visualization techniques to open black box data mining models," Inf. Sci. 225, 1-17 (2013).

92. R. Pontius and M. Millones, "Death to Kappa: birth of quantity disagreement and allocation disagreement for accuracy assessment," Int. J. Remote Sens. 32, 4407-4429 (2011).

93. M. Story and R. Congalton, "Accuracy assessment: a user's perspective," Photogramm. Eng. Remote Sens. 52, 397-399 (1986).

94. Q. McNemar, "Note on the sampling error of the difference between correlated proportions or percentages," Psychometrika 12, 153-157 (1947).

95. G. M. Foody, "Thematic map comparison: evaluating the statistical significance of differences in classification accuracy," Photogramm. Eng. Remote Sens. 70, 627-633 (2004).

Biographies for the authors are not available. 